\title{
Multiple Drug Resistance Pattern in Urinary Tract Infection Patients in Saudi Arabia
}

\author{
Shamweel Ahmad
}

Professor of Medical Microbiology and Consultant Microbiologist, Department of Clinical Laboratory Sciences, College of Medical Sciences, Prince Sattam Bin Abdul Aziz University, Kingdom of Saudi Arabia

[Received: 17 March 2018; Accepted: 12 April 2019; Published: 1 June 2019]

\begin{abstract}
Background: Urinary tract infection (UTI) is the most common problem in hospitalized and outdoor patients. It is mainly found in females because of the shortness of the urethra and closeness to anus, which facilitate entrance of fecal micro-flora to urinary tract. Knowledge of local antimicrobial resistance patterns is essential for evidence- based empirical antibiotic prescribing. Objective: The main aim of this study was to analyze the drug resistance pattern of bacterial isolates from suspected urinary tract infection (UTI) patients in Al-Kharj, Saudi Arabia. Methodology: This cross- sectional study was carried out in Al-Kharj region of Saudi Arabia from 1 ${ }^{\text {st }}$. September, 2016 to $28^{\text {th }}$. February, 2017. Midstream urine specimens were collected from patients at a general hospital. The specimens were cultured and the isolates were identified using standard microbiological techniques. The antibiotic susceptibilities of the isolates were also determined. Results: The number of patients with urinary tract infection who yielded positive cultures from their mid stream urine specimens was 249(12.0\%) out of 2064 specimens. The commonest isolates were Escherichia coli (53.4\%) and Klebsiella pneumoniae (28.5\%). Other bacterial pathogens were Proteus mirabilis (5.2\%), Pseudomonas aeruginosa (4.4\%), Streptococcus agalactiae (6.0\%) and Enterococcus faecalis. (2.5\%). Conclusions: E. coli is the most common causative agent of urinary tract infection followed by Klebsiella pneumoniae. Ampicillin, Augmentin, Cotrimoxazole, Norfloxacin and Nalidixic acid have the highest resistance rates against both these pathogens. No isolate is found to be resistant to imipenem. [Bangladesh Journal of Infectious Diseases $2019 ; 6(1): 3-7]$
\end{abstract}

Keywords: Multidrug resistance; Urinary Tract Infection; Imipenem

Correspondence: Dr. Shamweel Ahmad, Professor of Medical Microbiology and Consultant Microbiologist, Department of Clinical Laboratory Sciences, College of Medical Sciences, Prince Sattam Bin Abdul Aziz University, Kingdom of Saudi Arabia; Email: dr.shamweel@ psau.edu.sa; Cell no.: +966115886341

Conflict of interest: There is no conflict of interest to any of the authors of this article.

Funding agency: The study was not funded by any authority.

Contribution to authors: Shamweel Ahmad had searched the literature, had prepared the manuscript and had revised it properly How to cite this article: Ahmad S. Multiple Drug Resistance Pattern in Urinary Tract Infection Patients in Saudi Arabia. Bangladesh J Infect Dis 2019;6(1):3-7

Copyright: (2019. Ahmad. Published by Bangladesh Journal of Infectious Diseases. This article is published under the Creative Commons CC BY-NC License (https://creativecommons.org/licenses/by-nc/4.0/). This license permits use, distribution and reproduction in any medium, provided the original work is properly cited, and is not used for commercial purposes. 


\section{Introduction}

Urinary tract infections (UTIs) are amongst the most common infections described in outpatient settings. ${ }^{1,2}$ UTI are also the most common infections in acute and long term care hospital patients. ${ }^{3,4}$ There are an estimated 150 million urinary tract infection (UTI) per annum worldwide ${ }^{5}$. UTIs result in approximately 8 million physician visits and more than 100,000 hospital admissions per year in the United States ${ }^{6}$. These are the most common bacterial infections in women and account for significant morbidity and health care costs ${ }^{7}$. UTI may be asymptomatic in many cases, while it may be accompanied by dysuria, cystitis and pyelonephritis in other patients ${ }^{8}$. UTI are responsible for considerable morbidity and when associated with urinary obstruction or renal papillary damage, can lead to serious kidney damage.

UTI are a serious health problem affecting millions of people each year. In the USA, it is estimated from surveys of office practices, hospital-based clinics and emergency departments that there are over eight million cases of UTI annually ${ }^{9}$. The prevalence of asymptomatic bacteriuria in Sweden was reported as being between one and three percent from neonatal period to school age ${ }^{10}$, while in Saudi Arabia a prevalence rate of $5.3 \%$ was reported. ${ }^{11}$

The most common organisms causing UTI are $E$. coli while Proteus, Klebsiella, Streptococcus and Staphylococcus epidermis also commonly the causative agents. ${ }^{12}$ Both in community and hospital settings, antimicrobial resistance among uropathogens causing urinary tract infections is also increasing. ${ }^{13} \mathrm{E}$. coli is the most frequently found bacteria in UTI patients from both these settings which accounts for $80-90 \%$ of UTI cases. ${ }^{14,15}$

The predominant organisms associated with UTI in Saudi Arabia are Gram negative bacteria which are highly resistant to commonly used oral agents ${ }^{16}$. UTI in children are a significant source of morbidity, particularly when associated with abnormalities ${ }^{17}$. Vesico-ureteral reflux is the most commonly associated abnormality and reflux nephropathy is an important cause of end stage renal disease in children and adolescents ${ }^{18}$. However, when reflux is recognized early and managed appropriately, renal insufficiency is rare. Some adolescents who present with an apparently uncomplicated first urinary tract infection turn out to have considerable reflux. Subclinical infections can sometimes lead to severe bilateral renal scarring. Therefore, even a single documented urinary tract infection in an adolescent must be taken seriously. In this study, we determined the incidence of urinary tract infections in adolescents in Al-Kharj, Saudi Arabia; identified the uropathogens responsible for the infection; and studied the patterns of antibiotic sensitivity of the uropathogens. This was all done in order to ascertain appropriate antibiotic treatment therapy. Although UTI is a major problem for the community at large, there is lack of reports about the causative agents of UTI's and their treatment in Al-Kharj city of Saudi Arabia. The main aim of this study was to look at the different bacteria causing UTI with their antimicrobial resistance pattern among Saudi population.

\section{Methodology}

This cross- sectional study was carried out in AlKharj region of Saudi Arabia. Consecutive freshly voided mid-stream urine (MSU) specimens were submitted by the patients attending at military Hospital in Al-Kharj, Saudi Arabia during the period $1^{\text {st }}$. September, 2016 to 28 February, 2017. The patients were suspected of suffering from symptoms of UTI. Standard microbiological techniques were used in the culture of all MSU specimens and in the identification of the isolates. ${ }^{19}$ All urine specimens were inoculated sheep blood agar plates and cysteine lactose electrolyte deficient media. These plates were incubated aerobically at $37^{0} \mathrm{C}$ for 18 to 24 hours. The plates were read at the end of the incubation period. All isolates were identified using standard biochemical tests. In addition commercially available biochemical kits, API 20E (bioMerieux, France) were also used for the identification of enteric pathogens. Antibiotic sensitivity testing was performed using the disc diffusion method on Mueller-Hinton agar plates. The antibiotics tested on each disc were ampicillin (25 $\mu \mathrm{g})$, cotrimoxazole (1.25/ 23.75 $\mu \mathrm{g})$, ceftriaxone $(30 \mu \mathrm{g})$, augmentin $(20 / 10 \mu \mathrm{g})$, cefuroxime $(30 \mu \mathrm{g})$, cefotaxime $(30 \mu \mathrm{g})$, piperacillin $(100 \mu \mathrm{g})$, nalidixic acid $(30 \mu \mathrm{g})$, nitrofurantoin $(300 \mu \mathrm{g})$, norfloxacin $(30 \mu \mathrm{g})$, ciprofloxacin $(30 \mu \mathrm{g})$, gentamicin $(10 \mu \mathrm{g})$, amikacin $(30 \mu \mathrm{g})$ and imipenem $(30 \mu \mathrm{g})$. Results of disk diffusion method were interpreted in accordance to the Clinical and Laboratory Standards Institute. ${ }^{20}$

\section{Results}

A total number of 2064 urine specimens were cultured of which 1280 females and 764 males between $1^{\text {st }}$. September, 2016 to $28^{\text {th }}$ February, 
2017. All the specimens were processed in the Microbiology Laboratory of College of Medical Sciences, Prince Sattam bin Abdul Aziz University, Al-Kharj. Of the 2064 specimens, 249 (12.0\%) showed positive urine culture.

Table 1 Prevalence of urinary tract infection among tested patients in relation to gender

\begin{tabular}{|l|c|c|c|}
\hline \multirow{2}{*}{ Gender } & \multicolumn{2}{|c|}{ Culture } & \multirow{2}{*}{ Total } \\
\cline { 2 - 3 } & Positive & Negative & \\
\hline Males & $109(43.8 \%)$ & $\boldsymbol{?}$ & $764(? ? \%)$ \\
\hline Females & $140(56.2 \%)$ & $\boldsymbol{?}$ & $1280(? ? \%)$ \\
\hline Total & $\boldsymbol{?}$ & $\boldsymbol{?}$ & $\mathbf{2 0 6 4}(? ? \%)$ \\
\hline
\end{tabular}

Among those who gave a urine sample for culture a slightly higher proportion of females, $140(56.2 \%)$ had a positive urine culture as compared with males $109(43.8 \%)$ (Table 1).

Most of the isolates were Gram- negative organisms $228(91.6 \%)$ and Gram positive organisms constituted $21(8.4 \%)$ of all the isolates (Table 2 ).
Table 2 Organism isolated from urine cultures

\begin{tabular}{|l|c|c|}
\hline Isolated Bacteria & Frequency & Percent \\
\hline Escherichia coli & 133 & 53.4 \\
\hline Klebsiella pneumoniae & 71 & 28.5 \\
\hline Streptococcus agalactiae & 15 & 6.0 \\
\hline Proteus miribilis & 13 & 5.2 \\
\hline $\begin{array}{l}\text { Pseudomonas } \\
\text { aeruginosa }\end{array}$ & 11 & 4.4 \\
\hline Enterococcus faecalis & 6 & 2. \\
\hline
\end{tabular}

Antibiotic sensitivities: Among Gram negatives all isolates showed high resistance to Norfloxacin and Nalidixic acid. E. coli and K.pneumoniae were resistant to ampicillin, cotrimoxazole and augmentin and variably sensitive to Gentamicin, Amikacin, Piperacillin, Norfloxacin and Nalidixic acid. Pseudomonas aeruginosa were found to be $100 \%$ sensitive to Imipenem. Enterococcus faecalis and Streptococcus agalactiae showed high resistance to commonly used drugs against them. Both these organisms were fully sensitive to imipenem (100.0\%). All isolates both gram negative and gram positive were highly sensitive to imipenem only (Table 3).

Table 3: Antimicrobial Resistance pattern of uropathogens

\begin{tabular}{|c|c|c|c|c|c|c|c|c|c|c|c|c|c|c|}
\hline Organism & \& & $\sum_{i}^{U}$ & రิ & 売 & 눈 & 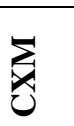 & $\sum_{0}^{N}$ & 䎹 & 㐏 & $\hat{E}$ & ชิ & $\mathbb{z}$ & $\begin{array}{l}\text { 苑 } \\
\text { 乙 }\end{array}$ & $\hat{i}$ \\
\hline $\begin{array}{l}\text { Escherichia } \\
\text { coli }(n=133)\end{array}$ & 96.2 & 96.2 & 94.7 & 79.0 & 79.0 & 79.7 & NT & 73.7 & 73.3 & NT & 90.2 & 91.0 & 91.0 & 0.0 \\
\hline $\begin{array}{l}\text { Klebsiella } \\
\text { pneumonia } \\
(n=71)\end{array}$ & 100 & 100 & 91.5 & 84.5 & 83.0 & 76.0 & NT & 74.6 & 80.0 & NT & 90.1 & 91.6 & 91.6 & 0.0 \\
\hline $\begin{array}{l}\text { Proteus } \\
\text { mirabilis } \\
(n=13)\end{array}$ & 100 & 100 & 92.3 & 84.6 & 84.6 & 100 & NT & 92.3 & NT & 92.3 & NT & 92.3 & 92.3 & 0.0 \\
\hline $\begin{array}{l}\text { Pseudomonas } \\
\text { aeruginosa } \\
(n=11)\end{array}$ & NT & NT & NT & 90.9 & 81.8 & NT & 81.8 & NT & NT & 81.8 & 72.7 & 72.7 & 81.8 & 0.0 \\
\hline $\begin{array}{l}\text { Streptococcus } \\
\text { agalactiae } \\
(n=15)\end{array}$ & 100 & 100 & 100 & 88.9 & 88.9 & NT & NT & NT & 88.9 & NT & 88.9 & 88.9 & 88.9 & 0.0 \\
\hline $\begin{array}{l}\text { Enterococcus } \\
\text { faecalis } \\
(n=6)\end{array}$ & 66.7 & 100 & 66.7 & NT & - & 83.3 & NT & NT & 83.3 & NT & NT & NT & NT & 0.0 \\
\hline
\end{tabular}

$\mathrm{AP}=$ Ampicillin, $\mathrm{AMC}=$ Augmentin, $\mathrm{COT}=\mathrm{Co}$-trimoxazole, $\mathrm{GEN}=$ Gentamicin, $\mathrm{AK}=$ Amikacin, $\mathrm{CXM}=$ Cefuroxime,

$\mathrm{CAZ}=$ Ceftazidime, $\mathrm{CRO}=$ Ceftriaxone, $\mathrm{NIT}=$ Nitrofurantoin, $\mathrm{PIP}=$ Piperacillin, $\mathrm{CP}=$ Ciprofloxacin, NA= Nalidixic Acid, NOR=

Norfloxacin, IMP= Imipenem, NT= Not Tested.

\section{Discussion}

This study shows the organisms causing UTI among the patients attending a general Hospital in
Al-Kharj. The rate of isolation of the urinary tract pathogens was in general agreement with others ${ }^{21}$. The number of female patients with UTI was more than the males, but the difference was not statistically significant. Higher prevalence of UTI 
among females ${ }^{22}$ is due to the factors that predispose women to UTI more than men. The most predominant urinary tract pathogen in both sexes in this investigation was E. coli and Klebsiella pneumoniae in concordance with other studies from Saudi Arabia ${ }^{23-26}$.

Resistance to antibiotics is highly prevalent in bacterial isolates worldwide, particularly in developing countries. The antimicrobial susceptibility of urinary pathogens have been changing over the years; both in the community and hospital settings. Factors such as unregulated antibiotic use in developing countries, extensive use and misuse of antimicrobial agents could all contribute to changes in the microbial profile of uropathogens. In the hospital setting most cases of UTI are initially treated empirically ${ }^{27}$.

In vitro drug sensitivity demonstrated a high prevalence $(>90.0 \%)$ of resistance among the strains of E. coli and Klebsiella pneumoniae to cotrimoxazole, a drug considered to be of choice in urinary tract infection. Similar results have been reported by others ${ }^{26}$. The high prevalence of resistance to the commonly used antibiotics such as cotrimoxazole and ampicillin have caused considerable alarm. The factors favoring development of antibiotic resistance include previous use of an antibiotic by the individual or wide spread use of antibiotics in the community. Antibiotic misuse is very common in developing countries, mainly because of failure to restrict the use of antibiotics in hospitals ${ }^{28}$. Pseudomonas aeruginosa, a common cause of hospital-acquired UTI, was found to be resistant to all the common antibiotics but sensitive to imipenem (100.0\%) corroborating with the results of others ${ }^{29}$. The other antibiotics showed high level of resistance against all the isolates in this study, which is in agreement with others ${ }^{30}$. The only antibiotics which showed $100 \%$ sensitivity against all isolates was imipenem. Similar results were reported by Mihankhah et $\mathrm{al}^{31}$. These higher resistance rates suggest that these antibiotics should not be selected for empirical treatment in our province. The reason for these higher resistance rates may be due to widespread use of common antibiotics in the hospital and crossresistance among different bacteria.

\section{Conclusion}

Almost all uropathogens isolated in this study have showed the menacing state of drug resistance. E. coli, K.pneumoniae and Proteus mirabilis were resistant to ampicillin, cotrimoxazole and augmentin. Pseudomonas aeruginosa showed resistance to gentamicin, amikacin, cetazidime. Enterococcus faecalis and Streptococcus agalactiae showed high resistance to augmentin, nitrofurantoin, ciprofloxacin and norfloxacin. In this setting, imipenem is the only appropriate therapy for patients suffering from UTIs. Regularly updated surveillances of local microbial prevalence and resistance patterns are needed to guide the empiric therapy for UTIs.

\section{References}

1. Stamm WE, Hooton TM. The management of urinary tract infection. N Engl J Med 1993;329:1328-1334

2. Warren JW, Abrutyn E, Hebel JR, Jhonson JR, Schaeffer AJ, Stamm WE. Guidelines for antimicrobial treatment of uncomplicated acute bacterial cystitis and acute pyelonephritis in women. Clin Infect Dis 1999;29:745-758

3. Gastmeier P. Nosocomial urinary tract infection: many unresolved questions. Clin Micro Infec 2001;7: 521-522

4. Nicolle LE, Strausbaugh LJ, Garibaldi RA. Infections and antibiotic resistance in nursing homes. Clin Microbiol Rev 1996;9:1-17

5. Stamm WE, Norrby SR. Urinary tract infections: disease panorama and challenges. J infect Dis 2001; 183(Suppl. 1):S1-S4

6. Warren JW, Abrutyn E, Hebel JR, Jhonson JR, Schaeffer AJ, Stamm WE. Guidelines for antimicrobial treatment of uncomplicated acute bacterial cystitis and acute pyelonephritis in women. Clin Infect Dis 1999;29:745-758

7. Gupta KA, Scholes D, Stamm WE. Increasing prevalence of antimicrobial resistance among uropathogens causing acute uncomplicated cystitis in women. JAMA 1999; 281:736-738

8. Karaou KM, Hanna A. An epidemiological study of urinary tract infections in Beighazi, Libya. J Hyg Epidem Microbiol Immu 1981;25:277

9. National Institutes of Health (1999). The National Kidney and Urologic Diseases Advisory Board 1999. Long Range Plan-window on the $21^{\text {st }}$ Century Publication No. 99: 583, Nite Bethesda, MD

10. Rudolph AM, Hoffman JE, Rodolph CD (1996). Rudolph's Paediatrics. Prentice Hall International. pp. 388-389

11. Omar EE, ElHaj AJ. Urinary tract infections in school children in Saudi Arabia. Med. Dig 1992;18: 3-7

12. Bonadio M, Costarelli S, Morelli G, Tartaglia T. The influence of diabetes mellitus on the spectrum of uropathogens and the antimicrobial resistance in elderly adult patients with urinary tract infection. BMC Infect Dis 2006;6:54

13. Bonadio M, Meini M, Spitaleri P, Gigli C. Current microbiological and clinical aspects of urinary tract infections. Eur Urol 2001;40(4):439- 445

14. Grüneberg RN. Changes in urinary pathogens and their antibiotic sensitivities, 1971-1992. J Antimicrob Chemother 1994;33(Suppl A):1- 8 
15. MacGowan AP, Brown NM, Holt HA, Lovering AM, McCulloch SY, Reeves DS. An eight-year survey of the antimicrobial susceptibility patterns of 85,971 bacteria isolated from patients in a district general hospital and the local community. J Antimicrob Chemother 1993;31(4):543-557

16. Al-Harthi AA, Al-Fifi SH. Antibiotic resistance pattern and empirical therapy for urinary tract infections in children. Saudi Med J. 2008;29(6):854-8

17. Ross JH. The evaluation and management of vesicoureteral reflux. Semin. Nephrol 1994;14:523-530

18. Bailey RR. Urinary tract infection. In: Westherall OJ, Ledingham JGG, Warrell D. (Eds). Oxford textbook of Medicine. 3rd edn Oxford; Oxford University Oress and Electron Publishing BV 1992; Section 6-7

19. Pezzlo M. Processing and interpretation of urine cultures. In: Isenberg HD, editors. Essential Procedures for Clinical Microbiology. Washington DC: American Society for Microbiology; 1998. p. 95-101

20.Performance Standards for Antimicrobial Disc Susceptibility Tests. Approved Standard-Eleventh Edition M02-A11. Vol. 32, No-1. National Committee for Clinical Laboratory Standards, Wayne, PA, USA, 2013.

21. Derevianko II, Khodyreva LA. Analysis of the etiologic structure of urinary tract infection and antibiotic resistance of its pathogens. Antibiotic-Khimioter 1997; 42: $27-32$

22. Hooton TM, Scholes D, Hughes JP, Winter C, Roberts TL, Stapleton AE et al. A prospective study of risk factors for urinary tract infection in young women. N Eng J Med 1996; 335: 468-574

23. Shamweel A, Ahmad F. Urinary tract infection at a specialist hospital in Saudi Arabia. Bangladesh Med. Res Counc Bull 1995; 21(3):95-98

24. Shamweel A. Pattern of urinary tract infection in Kashmir and antimicrobial susceptibility. Bangladesh Med Res Counc Bull 2012; 38: 79-83
25. Mohammed MA, Alnour TMS, Shakurfo OM, Aburass MM. Prevalence and antimicrobial resistance pattern of bacterial strains isolated from patients with urinary tract infection in Messalata Central Hospital, Libya. Asian Pacific Journal of Tropical Medicine 2016; 9(8): 771-776

26. Gunduz S, Altun HU. Antibiotic resistance patterns of urinary tract pathogens in Turkish children. Global Health Research and Policy 2018; 3:10

27. Gales AC, Jones RN, Gordon KA, Sader HS, et al. Activity and spectrum of 22 antimicrobial agents tested against urinary tract infection pathogens in hospitalized patients in Latin America: report from second year of the SENTRY Antimicrobial Surveillance Program (1998). J Antimicro Chemo 2000; 45: 295-303

28. Willett WC, Radoujui V. Urinary tract pathogens and antibiotic sensitivity patterns in Dar es salaam. East Afr Med. J. 1976; 53:685-92

29. Jones RN, Kaugler KC, Pfaller MA, Winokur PL. Characteristics of pathogens causing urinary tract infections in hospitals in north America. Results from the SENTRY Antimicrobial Surveillance Program, 1997. Diagn Microbil Infect Dis 1999; 35: 55-63

30. Khawcharoenporn T, Vasoo S, Singh K. Urinary Tract Infections due to Multidrug-Resistant Enterobacteriaceae: Prevalence and Risk Factors in a Chicago Emergency Department. Emer Med Intern 2013; 2013: 258517

31. Mihankhah A, Khoshbakht R, Raeisi M, Raeisi V. Prevalence and antibiotic resistance pattern of bacteria isolated from urinary tract infections in Northern Iran. J Res Med Sci. 2017; 22: 108 